\title{
INVESTIGACIÓN, INTERVENCIÓN Y DIDÁCTICA PARA LA CONSERVACIÓN Y RESTAURACIÓN DEL PARQUE ARQUEOLÓGICO DE COCHASQUÚ [ECUADOR]
}

\author{
RESEARCH, INTERVENTION AND EDUCATION FOR CONSERVATION AND RESTORATION OF THE \\ ARCHAEOLOGICAL PARK OF COCHASQUÍ [ECUADOR]
}

\section{BEGOÑA CARRASCOSA MOLINER, OLGA MEDINA LORENTE, ANDREA SANZ CATALÁ, CRISTINA NIETO PÉREZ}

\begin{abstract}
RESUMEN
Dado al creciente interés por la conservación del Parque Arqueológico de Cochasquí, y gracias al proyecto Cooperación al Desarrollo Cultural y Formativo para la Puesta en Valor de las Pirámides Preincaicas de Cochasquí, Ecuador, se realizaron unas labores de recuperación cuyos objetivos estaban orientados a la conservación y restauración de dos plataformas cerámicas ubicadas en la cúspide de la pirámide número 13 del complejo. Con la finalidad de recuperar estas manifestaciones, que se encontraban en un alarmante estado de deterioro, dicho proyecto desarrolló tres líneas de actuación, las cuales eran: la investigación de materiales de reposición en laboratorio, la restauración in situ y la apropiación social del patrimonio de Cochasquí, asegurando así, su salvaguardia. Todo ello gracias a la subvención del Ministerio de Asuntos Exteriores de España, a través de la Agencia Española de Cooperación Internacional al Desarrollo AECID, a la colaboración con la Universidad Politécnica de Valencia, España (UPV), y al Gobierno Autonómico Descentralizado de la Provincia de Pichincha, Ecuador.
\end{abstract}

\section{PALABRAS CLAVE}

Investigación, conservación-restauración, patrimonio sostenible.

\begin{abstract}
Due to the increasing interest in the conservation of the Archaeological Park of Cochasqui, and thanks to the project: Cultural Development and Cooperation for the Enhancement value of the pre-Incan Pyramids of Cochasquí, Ecuador, has developed several conservation and restoration actions for the recovery of two pre-Inca ceramic structures on pyramid number 13 of the archaeological complex. With the purpose of recovery these demonstrations, that were found in an alarming state of damage, this project developed three specific lines of action: the research on replacement materials in laboratory, in situ restoration, and social appropriation of the Cochasquí heritage, so as to guarantee its safeguard and protection. All thanks to the grant from the Spanish Ministry of Foreign Affairs through the Spanish Agency of International Cooperation for Development AECID, and the collaboration of Polytechnical University of Valencia, Spain (UPV) and Pichincha's Decentralized Provincial Government, Ecuador.
\end{abstract}

\section{KEY WORDS}

Research, conservation-restoration, sustainable heritage. 


\section{El Parque Arqueológico de Cochasquí y las plataformas cerámicas de la pirámide $\mathrm{n}^{\circ} 13$}

Ubicado a 3,100 msnm, en las faldas del nudo de Mojanda, se alza entre el bosque andino y el páramo pajonal el Parque Arqueológico y de Investigación Científica de Cochasquí (Ecuador), este debe su gran relevancia al ser uno de los pocos testimonios de la presencia de la cultura preincaica Quitu-Cara en la serranía del Ecuador, sumado a su interesante patrón de asentamiento urbano y su proximidad a la zona equinoccial.

Gracias a los estudios multidisciplinares que han intervenido y han aportado información relevante para el conocimiento del sitio, se sabe que nos encontramos ante un complejo constructivo que refleja una organización social comunitaria, ubicada en la última etapa de la historia antigua perteneciente al Periodo de Integración (500 a 1.500 d.C.). A. Meyers (1975) divide a la cronología de Cochasquí en dos periodos: Cochasquí I: A.D. 950 - 1250 y Cochasquí II: A.D. 1250 - 1550. Dicha descripción se basa en los fechados radiocarbónicos y a las características cerámicas de las excavaciones realizadas por Udo Oberem, ambos arqueólogos alemanes, en los años 60.

Entre las manifestaciones arquitectónicas se encuentra un conjunto de 15 pirámides truncas, 9 de ellas con rampa de acceso, además de 21 montículos o tolas circulares funerarias, todas ellas cubiertas bajo un manto vegetal de grama que se extienden en 83'9 Ha. En estas construcciones predomina el uso de bloques de cangahua tallada (loess o toba volcánica) adheridas entre sí con chocoto apisonado.

Dentro de los estudios multidisciplinares que se han ido desarrollando, se ha llegado a determinar que nos encontramos ante unas manifestaciones arqueológicas que reflejan un gran valor histórico-cultural para el patrimonio nacional ecuatoriano. Siendo reconocido por su valor y significancia cultural en algunas de las reuniones de la UNESCO, así como en varios foros nacionales e internacionales.

En 1979, Cochasquí es declarado Patrimonio Cultural de Ecuador en la Carta de Pichincha. Más tarde, en 1981 el H. Consejo Provincial de Pichincha da los primeros pasos encaminados hacia la conservación y salvaguardia del sitio arqueológico. Convirtiéndose al día de hoy en una Unidad Administrativa de la Corporación Provincial con la categoría de subdirección, de la Dirección de Cultura. Esta institución es la única encargada de la gestión y conservación de Cochasquí, bajo la supervisión del Instituto Nacional del Patrimonio Cultural.

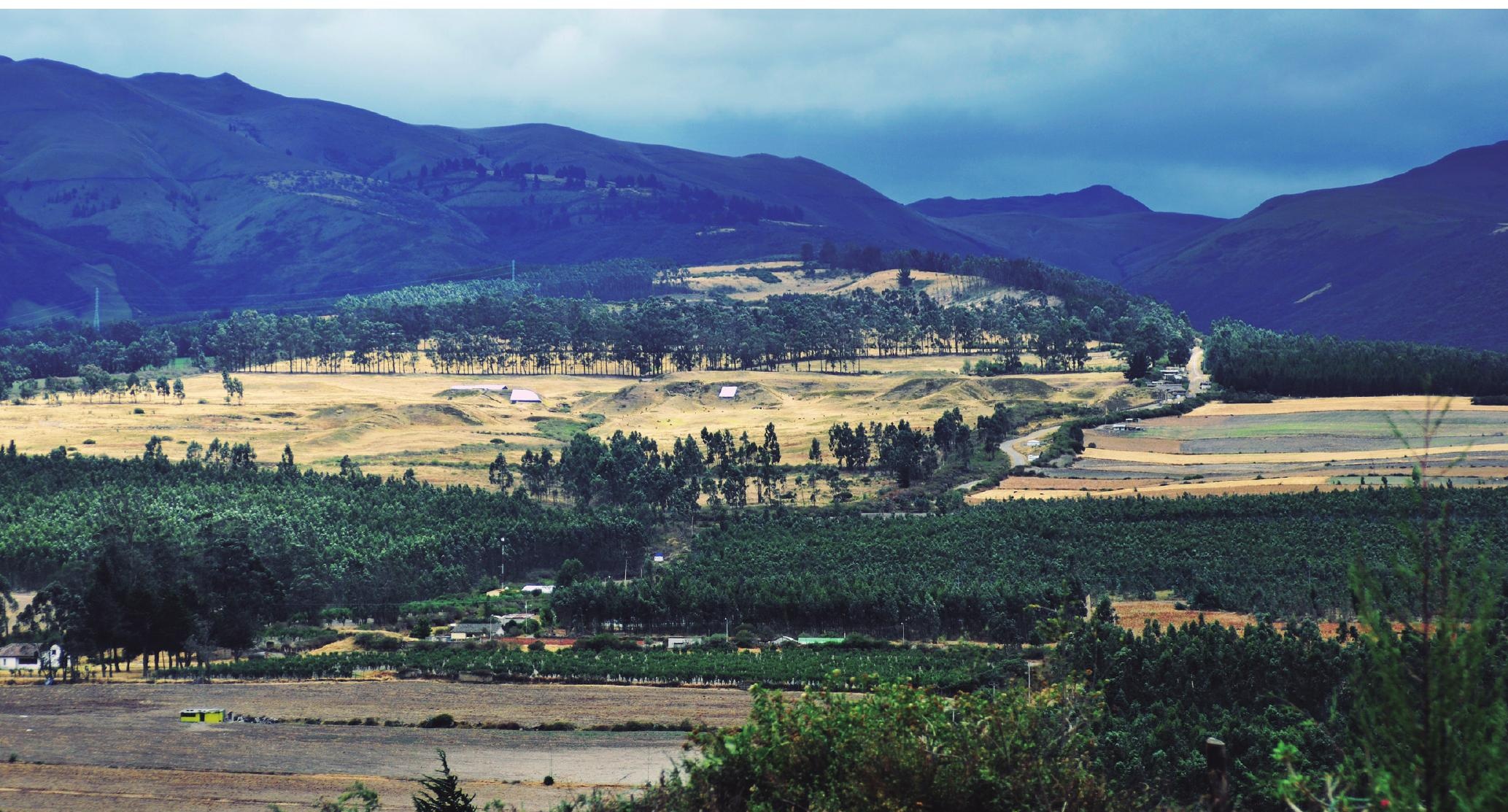




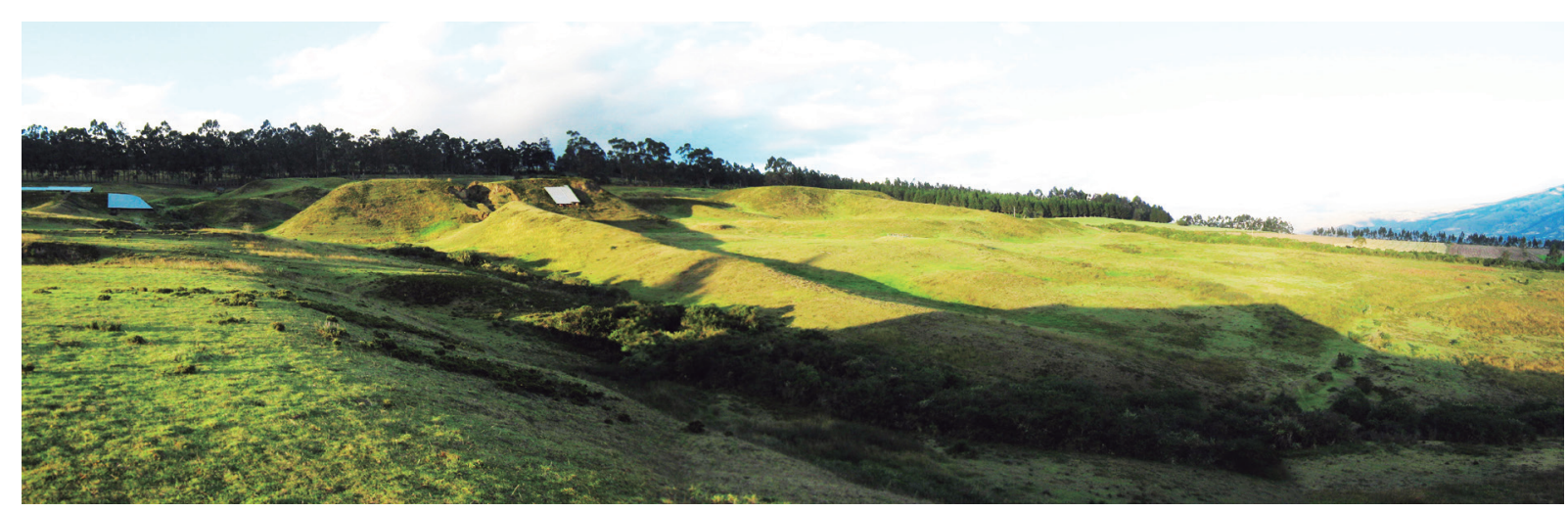

Figura 1 (página anterior)

Vista general del Parque Arqueológico desde la comunidad de Cochasquí.

Figura 2

Vista general de las pirámides, a destacar de izquierda a derecha la 13, la 9 y la 5.

Debido al grave estado de conservación en que se encontraban las plataformas cerámicas, por las causas ambientales, biológicas y antropológicas que han sufrido estos restos arqueológicos, y dado que en la actualidad la dirección del Parque muestra un importante interés en la conservación de los mismos, se ha llevado a cabo el proyecto: Cooperación el Desarrollo Cultural y Formativo para la Puesta en Valor de las Pirámides Preincaicas de Cochasquí, Ecuador, gracias a la subvención del Ministerio de Asuntos Exteriores de España a través de la Agencia Española de Cooperación Internacional al Desarrollo AECID, y a la colaboración con la Universidad Politécnica de Valencia, España (UPV), y el Gobierno Autonómico Descentralizado de la Provincia de Pichincha, Ecuador.

El objeto de las intervenciones de este proyecto comienza con la puesta en valor de las plataformas cerámicas. Se trata de dos plataformas circulares realizadas con barro modelado y cocido in situ. Estas superficies cerámicas fueron excavadas en 1964 por el arqueólogo alemán Udo Oberem y el 'Grupo Ecuador' conformado por científicos alemanes de la Universidad de Bonn.

Ambas están dispuestas en alturas diferentes, distando entre ellas la altura de $1 \mathrm{~m}$, siendo la plataforma inferior de aproximadamente unos $15^{\prime} 78 \mathrm{~m}$ de diámetro, frente a los 9'75 m de la superior. En ambas encontramos prácticamente los mismos elementos: la plataforma superior presenta dos cavidades longitudinales de poca profundidad, similares a canales que forman entre sí un ángulo agudo. Dentro de estas cavidades se encuentran seis orificios agrupados de tres en tres que conforman triángulos invertidos, y en cuyo interior se colocaban conos de piedra andesita. La estructura inferior presenta también dos canales aunque estos con quince orificios en el derecho y doce en el izquierdo, orientando la plataforma al norte.

Pese a que existen diversas hipótesis acerca de la funcionalidad que pudiera tener las plataformas cerámicas que están situadas en la cúspide de la pirámide n 13, sumado al conjunto de pirámides del Parque Arqueológico de Cochasquí, se imponen la planteada por el astrónomo ruso Valentin Yurevich (1984). La hipótesis establecía que el emplazamiento de las pirámides junto con estas plataformas era el idóneo para la observación astronómica, indicando que posiblemente, junto a los conos de piedra andesita (plintos) colocados en las oquedades de los canales que presentan estas plataformas cerámicas, esta cultura podía establecer los equinoccios y solsticios, asignando a la plataforma de mayor tamaño a la luz solar y la menor a la lunar.

Dichas superficies cerámicas, aunque en la actualidad se encuentran parcialmente protegidas mediante la construcción de un techado, años atrás estuvieron 


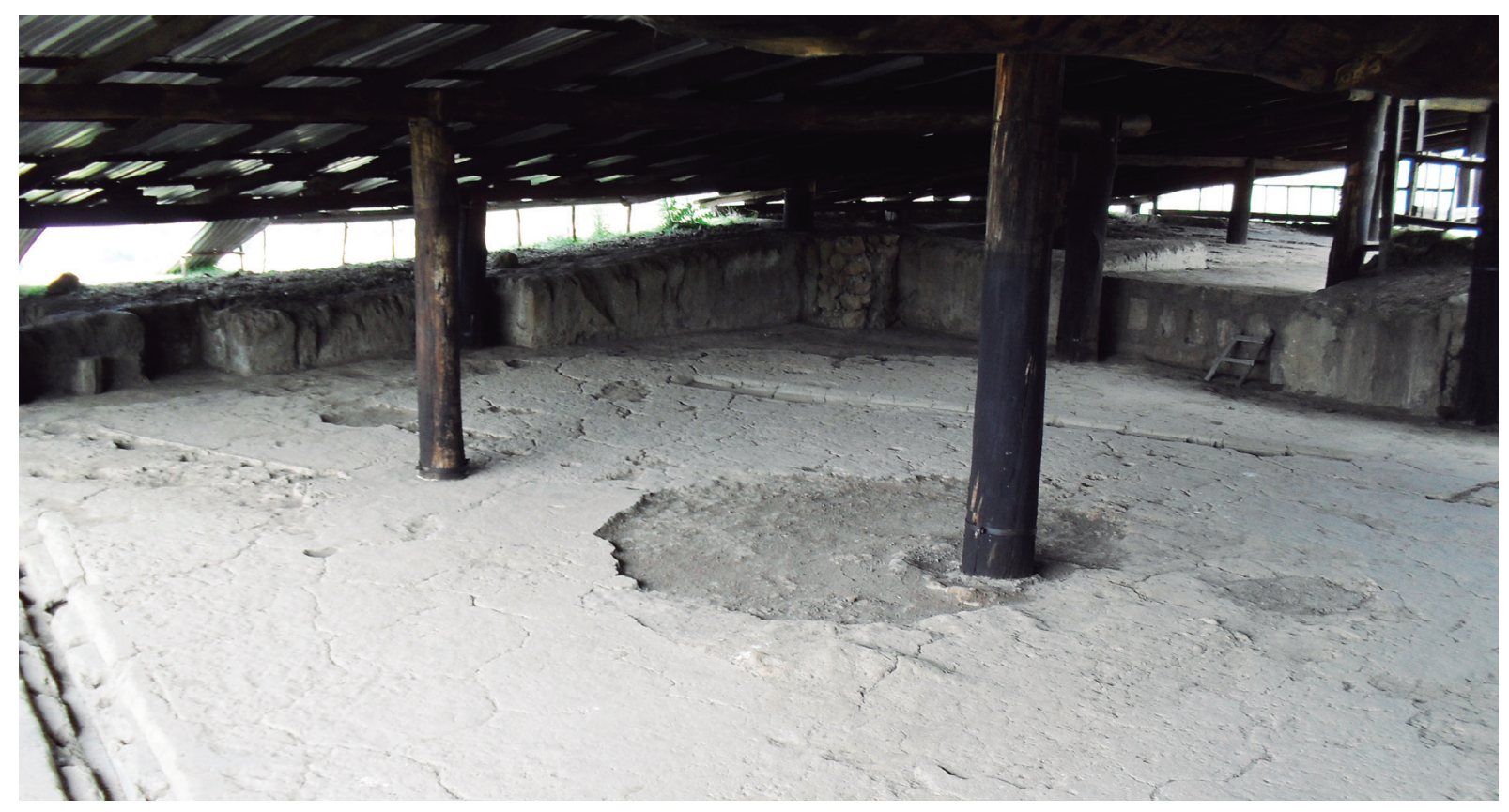

Figura 3

Vista general de las plataformas en su estado inicial.

expuestas en su totalidad a la intemperie tras ser excavadas por el arqueólogo alemán Udo Oberem en los años sesenta, por lo que han sufrido una serie de deterioros causados por varios factores climáticos, biológicos y de tipo antrópicos. Desde 1964 hasta 1981, el sitio no tuvo ningún tipo de atención en lo que respecta a su conservación, siendo expuesto a siembras indiscriminadas de piretro (planta para extraer piretrina y elaborar insecticida) y guanto. Los primeros trabajos de recuperación de la zona fueron destinados a estudios topográficos y conocimiento del estado de conservación, para proceder después a la eliminación de elementos que ponían en peligro la estabilidad de los monumentos, como plantas y arbustos. Sumando la acción de estos elementos con la de los agentes climáticos, se desarrollaron procesos de erosión y destrucción acelerada en algunos sectores que quedaron expuestos al exterior tras las intervenciones arqueológicas, contando entre ellos las plataformas que abarcan nuestro proyecto. Por lo que se precipitaron a cubrirlas empleando los materiales a los que podían tener acceso, así como el uso de tierra y construcción de vallas, y en otros casos la colocación de cubiertas y estructuras especialmente diseñadas y adaptadas lo mejor posible a las mani- festaciones primitivas, que precisaban urgentemente ser resguardadas. Estas labores, aunque han contribuido a la desaceleración del deterioro de las plataformas antes expuestas a la intemperie, no resultan suficientes, pues también se debe profundizar con más detenimiento en estudios e investigaciones sobre materiales óptimos y perdurables que garanticen la salvaguarda de este importante testimonio.

Estos hechos pudieron ser ratificados durante el inicio de la primera fase del proyecto, diagnosticándose elementos que continúan deteriorando el material cerámico. Siendo estos debidos principalmente a factores climáticos, como la acción del viento, la lluvia y de los ascensos y descensos de la temperatura y humedad relativa del ambiente donde se encuentra. Como consecuencia de los anteriores, se añaden los factores de tipo biológico, donde han hecho acto de presencia plantas y microorganismos en zonas puntuales de las superficies o del perímetro de las mismas. A estos elementos que contribuyen al deterioro del material arqueológico, se suman las incursiones de animales y personas, que conscientes o no, han generado un aumento en el estado de degradación de las superficies, generando abrasiones, micro-excavaciones, fracturas, erosiones, fisuras que contri- 
buyen al aumento de pérdidas del material cerámico que hacen peligrar su perdurabilidad. Por este motivo, y con la finalidad de favorecer la desaceleración de los agentes patógenos que contribuyen al rápido deterioro de este tipo de cerámicas junto con sus características intrínsecas, ya que son más sensibles al deterioro debido a su manufactura in situ puesto que fueron sometidas a un sistema de cocción irregular, no alcanzando los $200^{\circ} \mathrm{C}$ este tipo de cerámicas, requieren una serie de estudios en profundidad que determinen con plenas garantías, qué tipo de tratamiento y productos resultan más eficaces para garantizar la estabilidad y a su vez faciliten la legibilidad de estos bienes culturales.

Dichos estudios han sido desarrollados mediante el apoyo de los recursos científicos, realizándose acciones de conservación y restauración teniendo siempre en consideración el respeto de la instancia estética e histórica de las superficies, el reconocimiento de los materiales arqueológicos y añadidos, así como la reversibilidad de procedimientos. Haciendo de un modo u otro partícipe a la población cercana al Parque de la importancia de la conservación de los bienes ancestrales, garantizando así la sostenibilidad y viabilidad de estas acciones, contribuyendo así al enriquecimiento identitario de las poblaciones aledañas y favoreciendo su atractivo turístico.

\section{El Proyecto de Cooperación al Desarrollo Cul- tural y Formativo}

La permanencia y recuperación del patrimonio, incidiendo especialmente en las manifestaciones arqueológicas, radica fundamentalmente en las acciones de conservación y restauración, sin olvidar la viabilidad y sostenibilidad de nuestras acciones. Hecho que nos hace ser conscientes que de poco o nada sirven si no existen acciones paralelas que se preocupen por su mantenimiento, y el desarrollo de lazos que unan ese patrimonio con las colectividades responsables de su salvaguarda. La difusión de este tipo de acciones, resulta de primer orden, pues incrementan el interés hacia este tipo de intervenciones a favor de la preservación de cualquier bien, y contribuyen a profundizar en las investigaciones realizadas para ese fin, a la vez que aportan sensibilización y concienciación a la ciudadanía y, por tanto, a favorecer y enriquecer la memoria cultural e identitaria, tanto a nivel individual como colectiva de las comunidades que rodean en este caso el sitio arqueológico de Cochasquí. Por ello, este proyecto, aunque se desarrolla en dos fases, presenta acciones a favor de la perpetuación de los bienes culturales que engloba el Parque.

Como personal investigador en el campo de la conservación y restauración de bienes culturales, consideramos de gran importancia la actuación de un equipo interdisciplinar para el buen desarrollo de los trabajos. Desde la Universidad Politécnica de Valencia, se ha pretendido en todo momento aportar a este gran equipo el enfoque científico-técnico necesario para llevar a cabo una intervención conservativa y restaurativa adecuada de los materiales constitutivos, a las condiciones medioambientales y a la accesibilidad del Parque.

Se debe destacar que este proyecto aplica una política de conservación preventiva dentro de las acciones anteriormente mencionadas, siguiendo una metodología de trabajo que ha sido diseñada para responder a la problemática específica de estas plataformas, respetando los principios vigentes a nivel internacional, como la Carta de Venecia de 1964 y las recomendaciones de la UNESCO. Bajo las normas de respeto al original, reversibilidad de tratamientos y mínima intervención. Para la realización de una correcta actuación, esta ha de estar basada no solo en dichos criterios, sino que ha de estar respaldada en estudios y análisis que garanticen la compatibilidad de los productos a emplear, y además en que estos sean sostenibles y factibles con las condiciones climáticas donde está ubicada la obra.

El proyecto ha sido desarrollado tras un minucioso estudio sobre los antecedentes históricos de estas estructuras y su estado actual, asimilando la trascendencia cultural que estos vestigios tienen para la identidad y patrimonio ecuatoriano y ante la necesidad acuciante de mejorar las condiciones en las que se encuentra. Por ello, el objetivo principal se centró en paralizar el deterioro estructural, asegurando con ello la conservación del material cerámico de las 
plataformas, investigando el consolidante más afín a su composición y situación ambiental, garantizando, asimismo, esta conservación mediante la formación y capacitación del personal de mantenimiento del Parque, realizando al mismo tiempo acciones de sensibilización.

Durante la I Fase (2008-2010) se procedió primeramente a recabar la información necesaria con el fin de conocer todos los factores que intervienen en el proceso de conservación, obteniendo así una aproximación del lugar y de las condiciones ambientales en las que se desarrollaría dicha actuación. Durante esta toma de contacto se evaluó el estado de conservación de las plataformas cerámicas para determinar una correcta propuesta de intervención y una apropiada metodología de trabajo. Para ello, se recogieron muestras del material cerámico de las plataformas, con el fin de realizar estudios analíticos previos pertinentes en el laboratorio del Instituto Universitario de Restauración del Patrimonio IRP.

En la II Fase (2012), se procedió a la restauración de los faltantes cerámicos mediante la realización previa de investigación de materiales, que condicionaría los productos a emplear en la posterior actuación in situ. Estas tienen como objetivo abordar aquellas áreas perdidas que distorsionan la comprensión del conjunto arqueológico, convirtiéndose estas en protagonistas a los ojos del visitante, ya que solo se conserva el $75 \%$ en la plataforma solar y el $60 \%$ en la lunar. Mediante esta serie de intervenciones se ha pretendido devolver la dignidad del conjunto sin perder su carácter arqueológico, ampliando al mismo tiempo su atractivo al visitante al mejorar su comprensión.

Durante el periodo en que se realizaban los trabajos de recuperación, se desarrollaron de manera paralela acciones de carácter social, en aras del empoderamiento cultural de las comunidades aledañas al Parque. Dichas actuaciones quedaron establecidas en las siguientes líneas:

1. Continuación de las acciones de formación del personal de mantenimiento del Parque, instruyéndolos en nociones de conservación y restauración aplicadas a las plataformas. Capacitándolos para que ellos mismos puedan actuar en caso de necesidad en un futuro. Además, al mismo tiempo, esta formación enriquece sus conocimientos sobre el bien cultural, favoreciendo actitudes de estima y respeto.

2. Acciones de aproximación a la disciplina, a través del Seminario en Conservación y Restauración de Material Arqueológico Cerámico in situ, destinado a los alumnos de Restauración y Museología, impartido en la Universidad Tecnológica Equinoccial de Quito (UTE) y en el Parque Arqueológico de Cochasquí, cuyos objetivos fueron la sensibilización de los futuros profesionales del sector, en las dificultades que entraña la conservación de cerámica arqueológica in situ, junto con los tratamientos acordes para su intervención.

3. Por último, y segundo objeto de investigación en el proyecto, son las acciones de sensibilización destinadas a niños y jóvenes de los pueblos y aldeas cercanas al sitio arqueológico, con el fin, a su vez, de obtener información acerca del grado de interés de esta población juvenil, con respecto al patrimonio arqueológico que los rodea. A partir de los resultados obtenidos, se podría entablar y proponer unas pautas más concretas para futuras acciones de apropiación social en dicha zona.

Como objetivos complementarios a esta línea fue la aproximación del conocimiento Quitu-Cara a través de los elementos del Parque, aportando una cierta sensibilización e impulsando y fortaleciendo la visión del joven hacia su patrimonio autóctono, y del mismo modo el empoderamiento y apropiación del mismo en su acerbo cultural, tomándolo como testimonio de sus raíces históricas. Y dado que estas acciones se enmarcan dentro de un proyecto de recuperación y conservación de dos testigos histórico-culturales, se pretendía fomentar valores de respeto y estima por la salvaguardia de su patrimonio, así como la valoración de los trabajos de conservación y restauración de estos materiales arqueológicos, vinculando la realidad del presente con la cultura Quitu-Cara. Todas estas intenciones llevadas a cabo mediante una metodología lúdica como técnica pedagógica para el aprendizaje. 


\section{Metodología de las actuaciones}

Tras esta primera toma de contacto y del examen visual del material que se iba a intervenir, se pudieron observar distintos tipos de patologías de orígenes diversos que se hacían patentes y afectaban a varias zonas de las superficies de las dos plataformas. Entre dichas patologías cabe destacar principalmente:

- Descohesión del material cerámico

- Pulverulencia del material cerámico.

- Pérdida del material cerámico en forma de lagunas de mayor o menor tamaño y profundidad.

- Depósitos superficiales de tierra y partículas diversas.

- Grietas, fracturas y roturas en el material cerámico.

Debido a todas estas patologías observadas, se estudió la intervención conservativa más adecuada para frenar y minimizar el deterioro de la obra. De tal modo, la propuesta contempló tratamientos de limpieza y consolidación del material cerámico que presentaba un mayor grado de descohesión. Respecto al tratamiento de lagunas, se procedió a la realización de refuerzos perimetrales y a la nivelación de sus superficies con el fin de homogeneizar la visión estética del conjunto. Recuperándose la resistencia y homogeneidad, y proporcionando así una unidad global.

Partiendo de las indagaciones realizadas en esta primera fase, cabe destacar las investigaciones en labo- ratorio que garantizan la calidad de nuestras intervenciones, como la búsqueda del consolidante más afín a las características de las plataformas, y el estudio acerca de morteros reintegrantes.

La investigación acerca del consolidante tomó como punto de partida una serie de análisis para conocer los componentes y las características de la cerámica de las superficies. Posteriormente fue realizado un estudio comparativo entre consolidantes de naturaleza organosilícea, por ser un material similar en su composición. Para dicho estudio fueron empleados fragmentos originales consolidados con dos tipos de silicato de etilo. La acción de este consiste en la deposición de sílice amorfa, rellenando los huecos existentes (producto del estado de degradación), aglomerando la matriz del sustrato y aumentando en consecuencia la compresión del mismo. Realizándose, posteriormente, diversos análisis y ensayos de envejecimiento para determinar la penetrabilidad de los productos seleccionados y el comportamiento de las cerámicas tras su tratamiento. Profundizando en el conocimiento de la conservación de los materiales arqueológicos y la estabilidad de estas estructuras a largo plazo.

Gracias a estos estudios en laboratorio, fue seleccionado el producto Estel $^{\circ} 1100$, compuesto a base de silicato de etilo y polisiloxanos oligoméricos (hidrorrepelentes), realizándose la consolidación general

Figura 4

Dibujo realizado por un alumno de 8 años en las actividades de sensibilización.

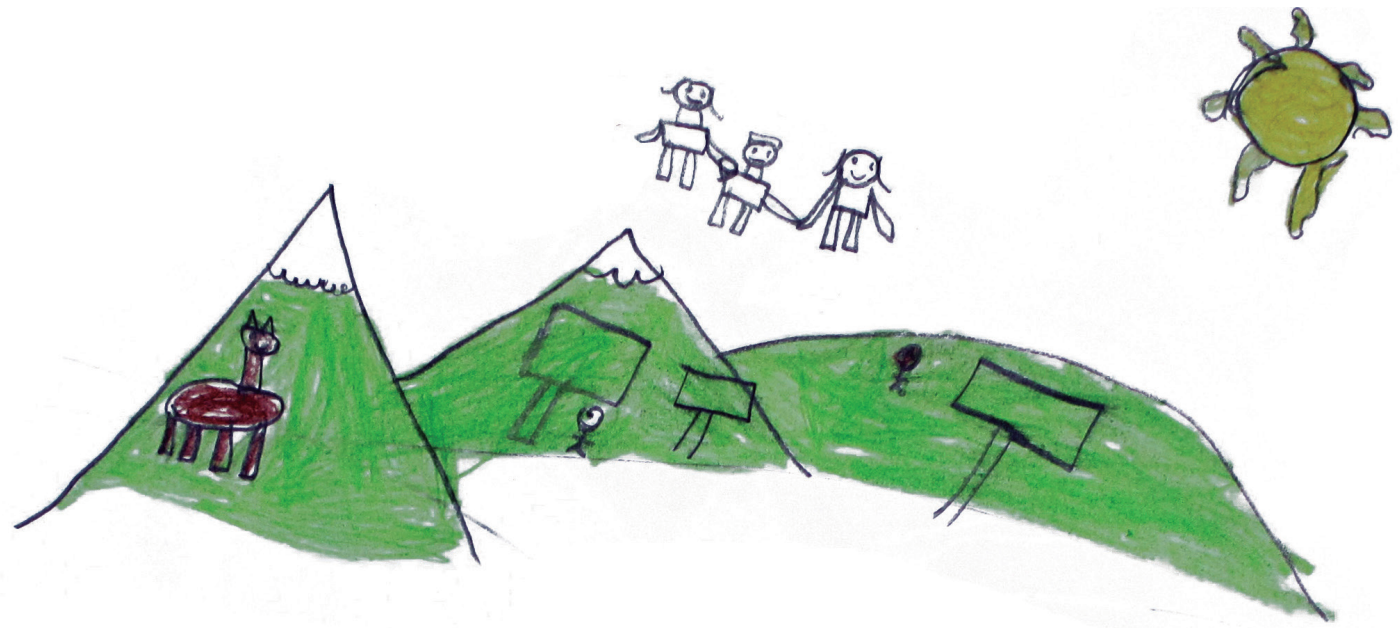



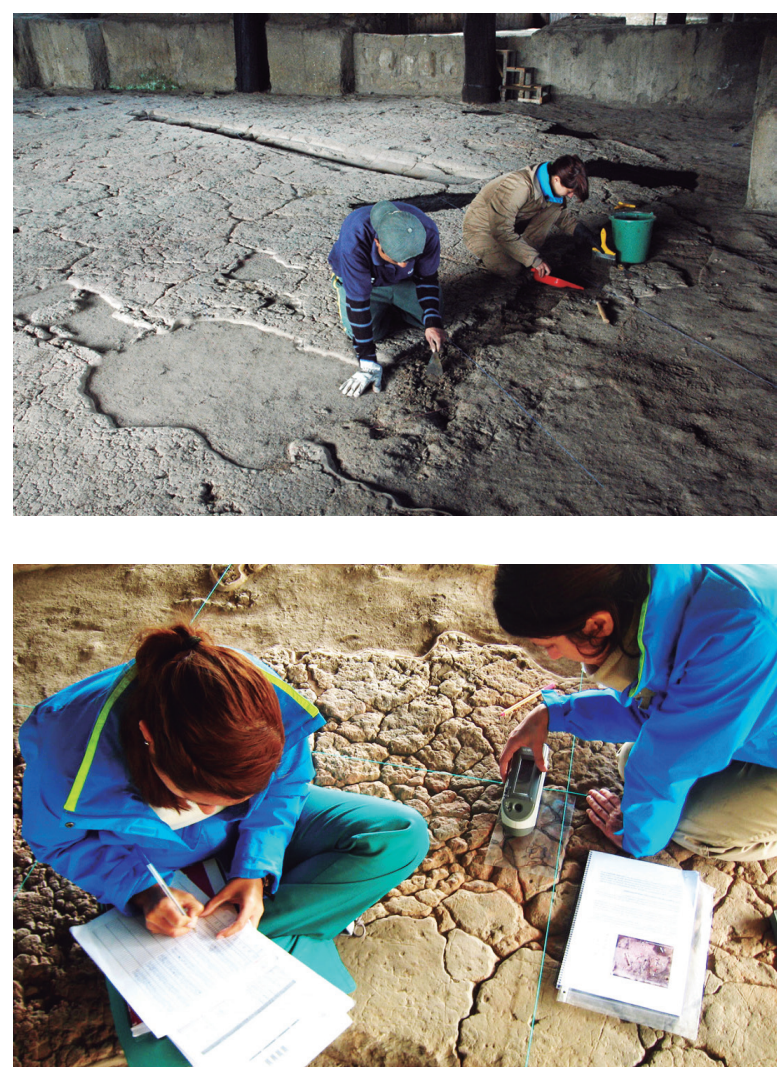

de la plataforma menor y una consolidación puntual en la plataforma mayor (Carrascosa, Medina, 2010).

Por otro lado, para garantizar la estabilidad y compatibilidad de los materiales de relleno con las cerámicas arqueológicas, fue llevado a cabo el estudio de la composición y comportamiento de los materiales que se han utilizando como morteros reintegrantes (Carrascosa B., Medina O., 2012). Se seleccionaron diferentes tipos de arcillas, cal y aditivos, en especial las resinas acril-vinílicas, realizando sobre todo análisis hídricos, ya que la presencia de agua es el principal desencadenante de agentes patógenos como la aparición de micro y macroorganismos, eflorescencias salinas, entre otros muchos factores que contribuyen a un cambio en su aspecto físico y estético. Estos morteros, son fácilmente reconocibles por el tono, facilitando el reconocimiento y la visualización del conjunto arqueológico. Por último, destacar que con la utilización de arcillas hemos facilitado la accesibilidad del material a los responsables de su mantenimiento, incluyendo de esta manera, el bajo coste económico, aportando

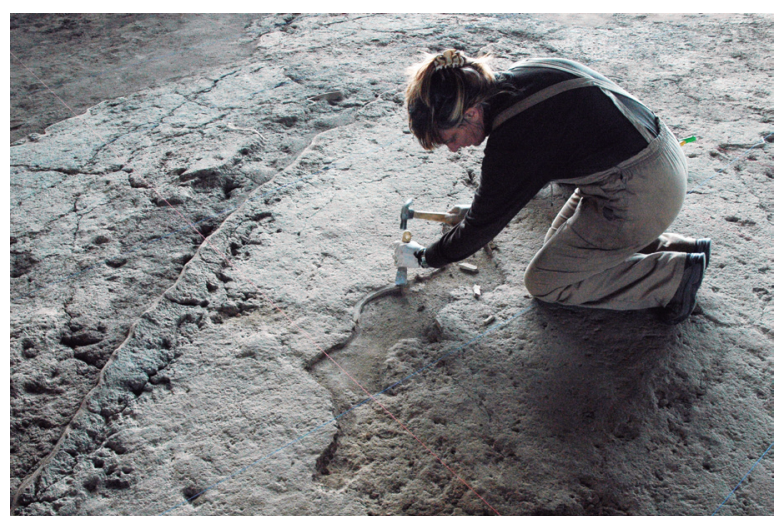

De izquierda a derecha y de arriba a abajo:

Figura 5

Eliminación de las tierras fijadas tras la Fase I.

Figura 6

Eliminación del refuerzo perimetral de la Fase I.

Figura 7

Personal técnico del proyecto realizando tomas de muestras colorimétricas de la cerámica.

viabilidad y sostenibilidad al proceso de restauración y a su mantenimiento a largo plazo.

El estudio previo muestra el camino seguido para determinar las características adecuadas de los materiales de reposición utilizados hasta la intervención directa en la reintegración volumétrica de las plataformas cerámicas. Investigando, tanto en España como en Ecuador, el material reintegrante más adecuado y afín al original desde el Laboratorio de Conservación y Restauración de Materiales Arqueológicos y Etnográficos del Instituto de Restauración del Patrimonio de la Universidad Politécnica de Valencia. Este estudio, es pues, la fase final del proceso de restauración, la reintegración volumétrica y colorimétrica mediante la investigación de morteros con diferentes arcillas y arcillas autóctonas de Ecuador a diferentes proporciones con la adición de cal.

Con los parámetros establecidos, se decidió escoger aquellos materiales más familiarizados con los componentes naturales de las cerámicas conocidas gracias a las muestras y ensayos extraídos durante la Fase I. Estos materiales iniciales fueron chamotas de 
diferentes granulometrías, arcillas de diferentes tipos, compuesto de Cal y Arena y combinaciones de cal con las arcillas, realizando diferentes ensayos y estudios en laboratorio que determinaron a las probetas compuestas por arcilla y cal con aditivo acril-vinílico al $10 \%$ como el mortero más adecuado para llevar a cabo la restauración de los faltantes cerámicos.

Tras los estudios previos, y teniendo en consideración las premisas de respeto al material original, reversibilidad de tratamientos y reconocimiento de los mismos, se desarrolló un plan de restauración que se expone a continuación y se caracteriza por acciones indirectas (fotografías, elaboración de mapas, registros colorimétricos y registro de humedad y temperatura) y acciones directas (labores de limpieza, restauración y protección del perímetro exterior):

En primer lugar, se procedió a la realización de un mimético registro fotográfico de toda el área cerámica y su perímetro, evaluando el estado de conservación de cada una sus partes e identificando sus nuevas patologías, para posteriormente proceder a la evaluación de lagunas a restaurar.

Las primeras acciones acometidas sobre las superficies, fueron los trabajos de limpieza, así como la preparación de las lagunas seleccionadas y el perímetro de las plataformas, eliminando los elementos añadidos en la primera fase de conservación, para proceder a las acciones de restauración volumétrica, la realización de nuevos rebordes perimetrales, así como la consolidación de material cerámico y morteros de relleno añadidos, y finalmente, la protección de las superficies perimetrales de las plataformas.

Paralelamente a las acciones de restauración, cabe mencionar que fueron realizadas operaciones indirectas en lo que respecta a la conservación preventiva de los restos, o lo que es lo mismo, al conocimiento ambiental en el que se encuentran y cómo se comportan los materiales expuestos a la intemperie. Para ello fue realizado un registro tanto de la humedad y temperatura presente en cada una de las superficies como del exterior, evaluando así las condiciones ambientales y el grado de eficacia de los elementos protectores de las superficies. Las mediciones fueron efectuadas cada 4 horas, obteniendo un total de 468 lecturas en cada uno de los tres aparatos. Con el mismo objeto, fueron realizadas evaluaciones colorimétricas, tanto en los materiales arqueológicos como en los materiales añadidos, antes y después de los tratamientos.

En cuanto a las acciones sociales desarrolladas paralelamente a los trabajos anteriormente descritos, cabe señalar que en cuanto a la capacitación y formación del personal de mantenimiento, los conocimientos impartidos fueron de carácter teórico-prácticos colaborando conjuntamente con los técnicos del proyecto.

En la sensibilización destinada a universitarios y futuros profesionales del sector en el Seminario impartido en la Universidad Tecnológica Equinoccial de Quito, la orientación del curso fue de carácter también teórica, complementada con sesiones prácticas en las plataformas intervenidas en el proyecto.

Y por último, en los trabajos de apropiación cultural destinados al público infantil y juvenil de escuelas y colegios próximos al Parque, el procedimiento empleado consistió en sesiones de charlas y coloquios en los centros escolares, complementada todas ellas con herramientas lúdico-didácticas, seleccionadas previamente de una investigación anterior desde el Taller de Arqueología del Instituto Universitario de Restauración del Patrimonio, en la Universidad Politécnica de Valencia.

\section{Desarrollo del proyecto}

\subsection{La restauración de las plataformas}

Estimación del estado de conservación y patologías:

Tras las actuaciones conservativas realizadas entre 2009-2010, caracterizadas por la realización de labores de limpieza y estabilización de las plataformas, en 2012 las plataformas presentaban unas condiciones propias de cualquier manifestación expuesta parcialmente a las condiciones ambientales, localizándose en ellas deterioros de tipo biológico, como la reaparición de dos pequeñas colonias de microorganismos, ubicadas cada una en el suroeste de ambas plataformas y también leves deterioros mecánicos.

La aparición de microorganismos, pudo ser consecuencia de la acción de la lluvia y la retención de la misma en esas áreas, puesto que el techado en estas 
zonas no es lo suficientemente amplio como para protegerlas. Los deterioros mecánicos se manifies$\tan$ en forma de pequeñas y leves erosiones de las superficies, encontrándose de forma puntual en la plataforma inferior y algo más amplia en la superior, estando relacionados con la incursión del personal sobre las plataformas para el mantenimiento de las mismas. Este deterioro es inevitable, pues sin el acceso del personal no pueden realizarse las acciones a favor de la conservación en las superficies y, por lo tanto, el deterioro sería mucho mayor. La incursión de animales salvajes en las plataformas es al día de hoy algo inevitable, ya que se encuentran techadas y rodeadas de barandas de madera y muros de cangahua, que solo impiden el acceso de animales de mayor tamaño, permitiendo, por tanto, la libre circulación de animales como es el ejemplo de la mofeta, muy común en estos parajes. Estos animales nocturnos realizan marcas en las áreas circundantes a las superficies, ocasionando pequeños orificios de forma puntual sobre las cerámicas. Otro de los elementos contribuyentes al deterioro cerámico son las deyecciones de las aves del entorno, estando presentes de forma generalizada en ambas superficies.

Limpieza y preparación de las superficies cerámicas y su perímetro

Tras el previo examen visual de las superficies, fueron detectadas leves alteraciones puntuales en ambas plataformas, encontrándose microorganismos, deposiciones de aves, afloramiento de plantas en el perímetro, acumulación de tierra y restos de materiales orgánicos transportados por el viento a las plataformas, erosiones en el material cerámico provocado por acción animal y humana, así como pequeñas ro- turas tanto en pavimento arqueológico como en los estucos de protección del mismo realizados durante la primera fase de intervención. Mediante el análisis e identificación de estas alteraciones, la metodología de trabajo para la recuperación volumétrica de las superficies cerámicas estuvo caracterizada por los siguientes tratamientos:

Como es habitual en este tipo de tareas, se procedió a la eliminación mediante acciones mecánicas de los restos de tierra y material orgánico disperso tanto sobre las plataformas como en su perímetro interior y exterior. Este procedimiento es evidentemente necesario, ya que con su realización previene el crecimiento de vegetación, debiéndose de repetir periódicamente. El método de eliminación de estas sustancias fue ejecutado mediante brochas de cerda blanda y sin hacer presión sobre las superficies. En cuanto a la eliminación de las diversas deposiciones de aves, se procedió a su erradicación mediante limpieza mecánico-física, a través del empleo de hisopos de algodón humectados en alcohol, con la finalidad de ablandar estas sustancias sin provocar una humedad excesiva sobre la superficie cerámica, facilitando así su eliminación mediante el empleo controlado de bisturís. En este tipo de intervenciones en el exterior, las acciones de limpieza mecánica para la eliminación de suciedades terrosas y de polvo transportado por el aire son frecuentes, en este caso concreto fueron realizadas durante varias fases de la actuación restaurativa: efectuándose una limpieza completa antes de la intervención de restauración, limpiezas puntuales en las zonas de tratamiento de lagunas, limpieza general tras la restauración y limpieza final tras los tratamiento de consolidación de las plataformas. Una vez limpio los pavimentos de las sustancias
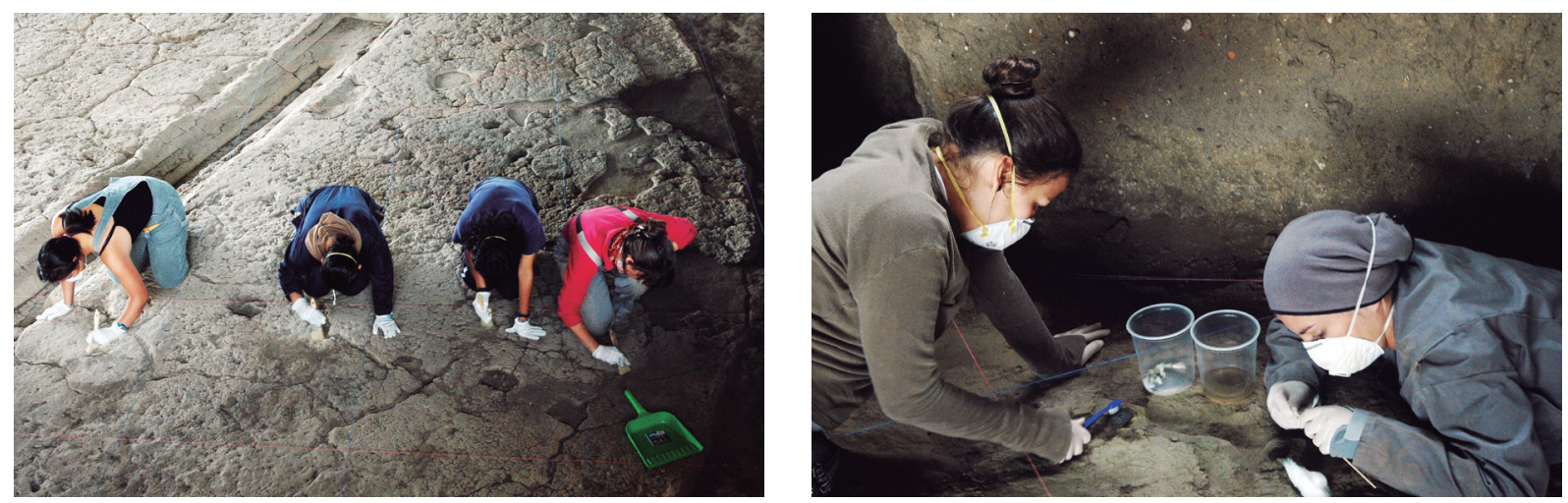

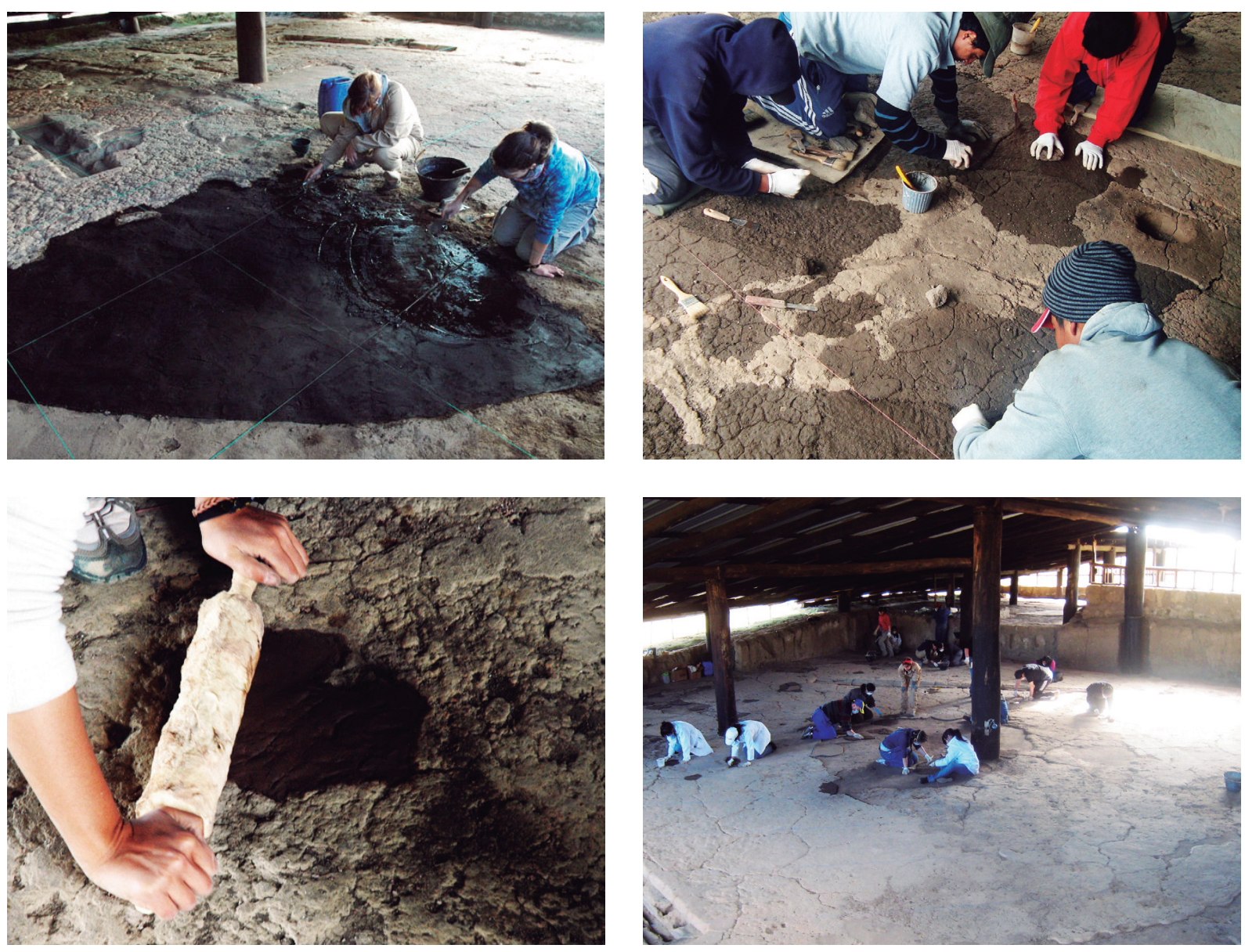

terrosas y partículas diversas, se procedieron a la eliminación de colonias de microorganismos, aparecidas en dos pequeñas áreas de las plataformas; estando una de ellas localizada en un pequeño margen del sector uno, perteneciente a la plataforma superior y otra situada en el sector tres de la plataforma inferior.

\section{Evaluación y restauración de lagunas seleccionadas}

Para poder llevar a cabo la restauración formal de las plataformas, fue necesario estudiar y valorar las zonas a intervenir. Por ello fue de especial interés la consulta de los mapas realizados por Wurster y la comparación de estos con la situación actual de las superficies. Pudiéndose observar una considerable pérdida de material cerámico, siendo mucho más acusada en la plataforma superior y no menos importante en la plataforma inferior. En ambas puede observarse una considerable pérdida, no solo de material cerámico, sino también de orificios cuya función se desconoce

De izquierda a derecha y de arriba a abajo:

Figura 8 (página anterior)

Estudiantes de la UTE y personal del proyecto realizando la limpieza mecánica en la plataforma inferior.

Figura 9 (página anterior)

Estudiantes de la UTE realizando la limpieza físico-mecánica de microorganismos.

Figura 10

Personal técnico del proyecto aplicando el chocoto en una de las lagunas de la plataforma inferior.

Figura 11

Personal del Parque durante los tratamientos de restauración volumétrica.

Figura 12

Texturización del mortero con rodillos.

Figura 13

Alumnos de la UTE desarrollando tareas de reintegración y restitución. 


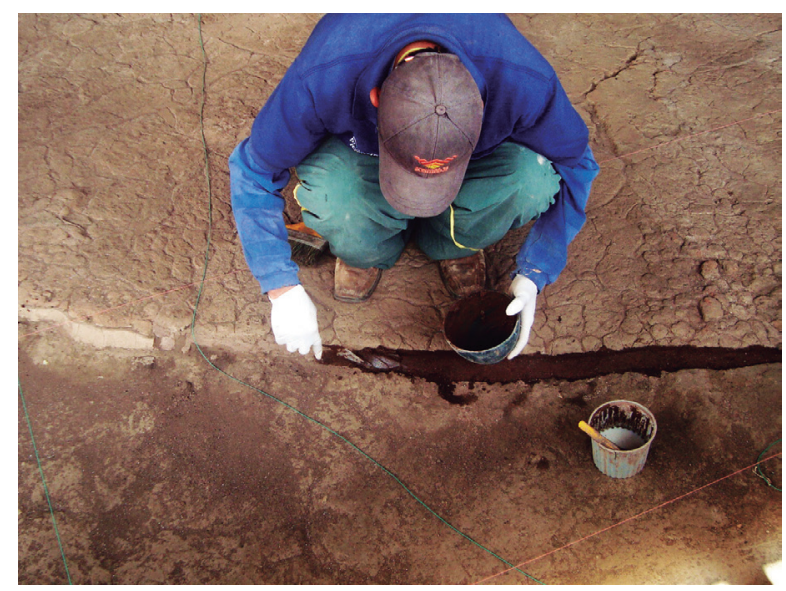

actualmente, desvirtuando futuras hipótesis respecto al uso de estas manifestaciones.

Por ello, se ha pretendido recuperar estas pérdidas con la intención de mostrar estos testimonios culturales tal y como fueron descubiertos, favoreciendo así futuras investigaciones que devuelvan el significado de estas manifestaciones desde el plano de vista socio cultural y ayudando, además, al espectador a comprender así sus formas iniciales, contribuyendo de tal modo a aumentar el valor de estas estructuras. Todo ello, mediante una intervención respetuosa con el material arqueológico, garantizando su óptima conservación y facilitando su lectura a los visitantes.

Con el propósito de incorporar nuevos materiales de reconstrucción en el interior de las lagunas, fue necesario realizar acciones de eliminación de morteros de protección perimetral localizados en las zonas a intervenir, así como el levantamiento de las costras de tierra fijadas en cada una de las lagunas anteriormente intervenidas durante los trabajos realizados a través de la primera fase del proyecto. La eliminación de dichos elementos fue llevada a cabo mediante el uso de escalpelos, cinceles y bisturís, efectuándose el retiro de forma controlada. Con las lagunas abiertas se procedió a ajustar los distintos niveles de profundidad de cada una de las lagunas igualándolas hasta alcanzar aproximadamente unos dos centímetros de fondo con respecto al nivel de la superficie cerámica; a su vez, se dibujaron y definieron las zonas perdidas de la periferia de las plataformas, con el propósito de preparar estas para la fase de reintegración volumétrica.

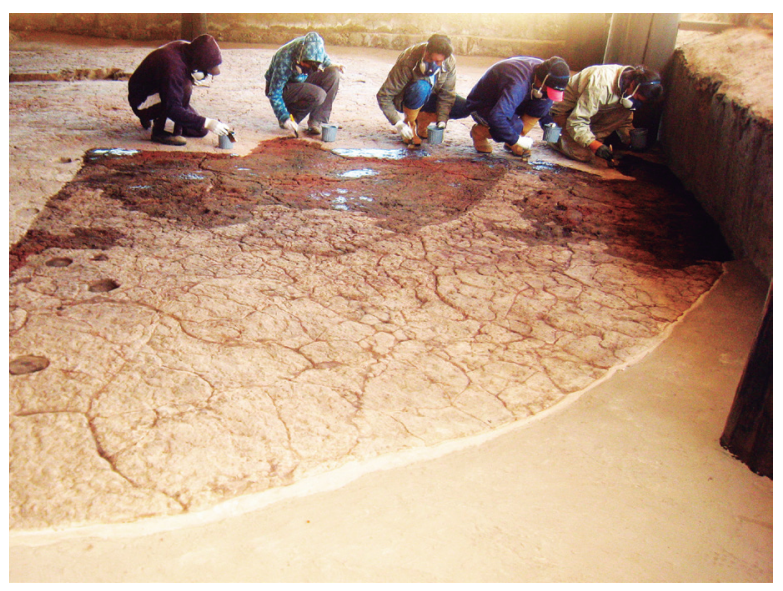

\section{Restauración volumétrica de las plataformas}

Con el propósito de nivelar las superficies irregulares que conforman las pérdidas de material y adaptar estas a las condiciones necesarias para llevar a cabo la reintegración formal, a la vez que se tiene en consideración un grosor estimado en torno a un centímetro de espesor, para la colocación de los morteros estudiados, fue utilizado chocoto (barro negro rico en limos), muy común en la zona. Este material, empleado por los antiguos moradores para la elaboración de sus construcciones, todavía continúa siendo parte de los materiales de construcción, tanto por su resistencia, como por su fácil preparación, sostenibilidad y bajo coste económico.

Como han podido extraerse de las conclusiones obtenidas tras los ensayos en laboratorio, el mortero seleccionado para la reintegración volumétrica fue el compuesto por arcilla y cal (3:1), formado por materiales propios del área, con un aporte de resina de tipo acril-vinílica. La elaboración de los morteros de relleno fue realizada mediante el uso de arcillas (pastas hidratadas) con cal al $10 \%$ en resina.

El método de intervención fue diseñado en la realización de pequeñas, medianas y grandes planchas, teniendo en cuenta la dominación de las fisuras presentes en la cerámica, y poder llevar a cabo una mayor integración entre los materiales añadidos y el material arqueológico. La aplicación de los morteros fue realizada mediante presión manual y para conseguir una texturación similar al material cerámico, se recurrió al uso de rodillos texturizados intercalándose con el estampado de brochas y piedras irregulares, de acuer- 
do con la complejidad de la texturación real. Conforme las pellas de arcilla y cal endurecían, fueron adheridas mediante el empleo de morteros elaborados con cal y tierras al $20 \%$ en resina acril-vinílica.

Completada la reintegración volumétrica de las plataformas, quedaron varias zonas intervenidas de la periferia sin la protección adecuada. Con la finalidad de proteger los perímetros de los nuevos bordes hechos con los morteros de arcilla y cal, se procedió a la realización de nuevos rebordes perimetrales, dado el óptimo comportamiento y la eficacia que ha supuesto este tipo de protección para las plataformas durante los dos años transcurridos.

\section{Consolidación del material cerámico y morteros.}

Teniendo en cuenta el estado de cohesión en el que se encontraban las plataformas, se decidió llevar a cabo una nueva actuación de consolidación del material arcilloso. Pese al buen estado de conservación, fue considerado oportuno prolongar el efecto conglomerante de este tipo de consolidantes, ya que según indican las investigaciones realizadas acerca de estas sustancias, su acción no es permanente en el tiempo, siendo conveniente repetir el tratamiento cada 3 o 5 años. Por ello se estimó oportuno repetir esta operación, dado que habían pasado dos años desde su primera aplicación. Verificando de este modo su eficacia y reforzando su efecto, favoreciendo, por tanto, a la correcta conservación del material arqueológico. El consolidante empleado para tal propósito fue nuevamente el silicato de etilo con características hidrofugante, investigado en la fase anterior de este proyecto y resultando ser el más respetuoso y

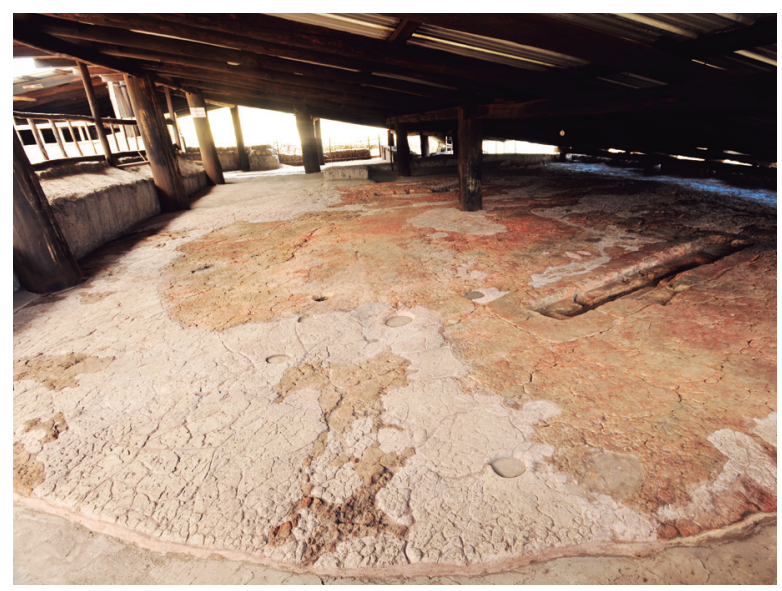

eficaz, según los análisis realizados en laboratorio y, por tanto, el más adecuado para la conservación del material cerámico. La consolidación en la plataforma superior fue realizada a nivel general en toda la superficie abarcando también los morteros de relleno realizados una vez secos y en la plataforma inferior, que debido a su mejor estado de conservación, fue realizada puntualmente.

Los resultados tras la restauración son claramente evidentes, pudiéndose observar como en la plataforma inferior se ha recuperado gran parte de su forma circular de acuerdo con los fragmentos conservados, los cuales fueron utilizados como referencia, recuperándose formalmente desde pequeñas a grandes lagunas. En cuanto a la restauración de la plataforma superior, su reintegración circular es prácticamente completa, pudiéndose subrayar el rescate de grandes lagunas como las situadas al noroeste y noreste de dicha plataforma.

También fueron realizadas otras series de acciones con la finalidad de contribuir a una mejora de la protección del entorno, así como las condiciones de exposición al público y facilidad de tránsito al personal de mantenimiento. Todo ello mediante el recrecimiento de muros, cerramiento de accesos, así como la disposición de una escalera entre las plataformas.

Es importante añadir que la intervención realizada ha quedado registrada mediante una exhaustiva documentación fotográfica en forma de mapas que reflejan el antes y el después de la intervención, mostrando al espectador los espacios donde antes existían faltantes cerámicos y la posterior reconstrucción 
de los mismos. Esta información es transmitida a todo aquel que visita las plataformas mediante afiches ubicados junto a las superficies intervenidas.

\subsection{Acciones sociales desarrolladas}

La capacitación del personal fue llevada a cabo mediante su implicación en los trabajos de conservación y restauración, las labores impartidas consistieron en una serie de actuaciones teórico-prácticas donde se desarrollaron los siguientes apartados, dando lugar al desarrollo de cualidades y aptitudes que les cualifican en la realización de labores de conservación y restauración puntuales en caso de necesidad:

- Limpieza de las plataformas cerámicas: eliminación de tierra superficial, agentes bióticos y antrópicos.

- Metodología de eliminación de intervenciones anteriores (tierra fijada y rebordes perimetrales).

- Elaboración y aplicación de morteros de relleno de lagunas.

- Sistemas de estampación de texturas de los morteros de relleno: aproximación formal.

- Metodología y proporciones morteros de tierra y cal para la adhesión de planchas de mortero de arcilla y cal.

- Elaboración de estucos para la creación de rebordes perimetrales: tipos de cargas según el cromatismo de las superficies, proporciones y modos de manejo.

- Elaboración y aplicación de adobe protector de las superficies terrosas circundantes a las plataformas cerámicas.

- Consolidación con silicato de etilo: metodología de aplicación y seguridad obligada del usuario.

- La conservación preventiva como método para la preservación del material cerámico y del material añadido tras la intervención.

En cuanto al Seminario sobre Conservación y Restauración de Material Cerámico Arqueológico in situ, fue realizada una presentación de los estudios previos, diagnóstico de las patologías, las diferentes técnicas de limpieza de material cerámico, consolidaciones por diferentes métodos, aplicaciones de reconstrucción volumétrica y sistemas de obtención de moldes, junto con los productos adecuados para la protección final al exterior, y técnicas para el control preventivo de los bienes expuestos a la intemperie. Los contenidos fueron parte del seminario impartido a los futuros profesionales de conservación-restauración. Del mismo modo, se enfatizaron los criterios deontológicos de la disciplina, como el empleo de productos inocuos, la necesaria distinción de la intervención y la importancia de preservar la lectura del bien una vez intervenido. A su vez, estuvo complementado con prácticas in situ, lo que les permitió desarrollar los conceptos teóricos aprendidos, dando como resultado la sensibilización en cuanto la dificultad que entraña la conservación de material arqueológico al exterior. El éxito del curso y las sesiones prácticas dio como resultado la posibilidad de realizar pasantías de 3 semanas a 9 estudiantes en el sitio arqueológico, en colaboración con los técnicos del proyecto y el personal trabajador del Parque Arqueológico de Cochasquí.

\section{ENSIBILIZACIÓN A LOS ESCOLARES COLEGIOS PRÓXIMOS AL PARQUE SE EL LEGAR ESTOS TESTIGOS}

Nuestro interés por la sensibilización a los escolares y jóvenes alumnos de los colegios próximos al Parque se debe a que de ellos dependerá el legar estos testigos culturales en las mejores condiciones posibles, como pilares del futuro que son. Precisamente en este sentido, la apropiación social del patrimonio repercute en el uso y cuidado de los bienes, y por tanto, en su conservación. Es decir, la población se convierte en una herramienta de conservación "preventiva", en la medida en que es consciente de que su conducta mantiene o altera la salvaguardia del objeto.

Los colectivos que participaron en la experiencia se localizan en los colegios y escuelas de los pueblos aledaños al sitio arqueológico, siendo la Escuela 13 de abril de la comunidad de Cochasquí, la Escuela Fiscal Mixta Pedro Moncayo y Colegio Nacional Malchinguí de la comunidad de Malchinguí, con un total de 612 alumnos participantes, entre edades comprendidas desde los 5 a los 18 años.

La metodología arrancó con unos estudios sobre el estado de la educación patrimonial en el Ecuador, además de la recopilación de estudios y experiencias previas en apropiación social del patrimonio. Finalmente, sujetos a las condiciones y posibilidades del 

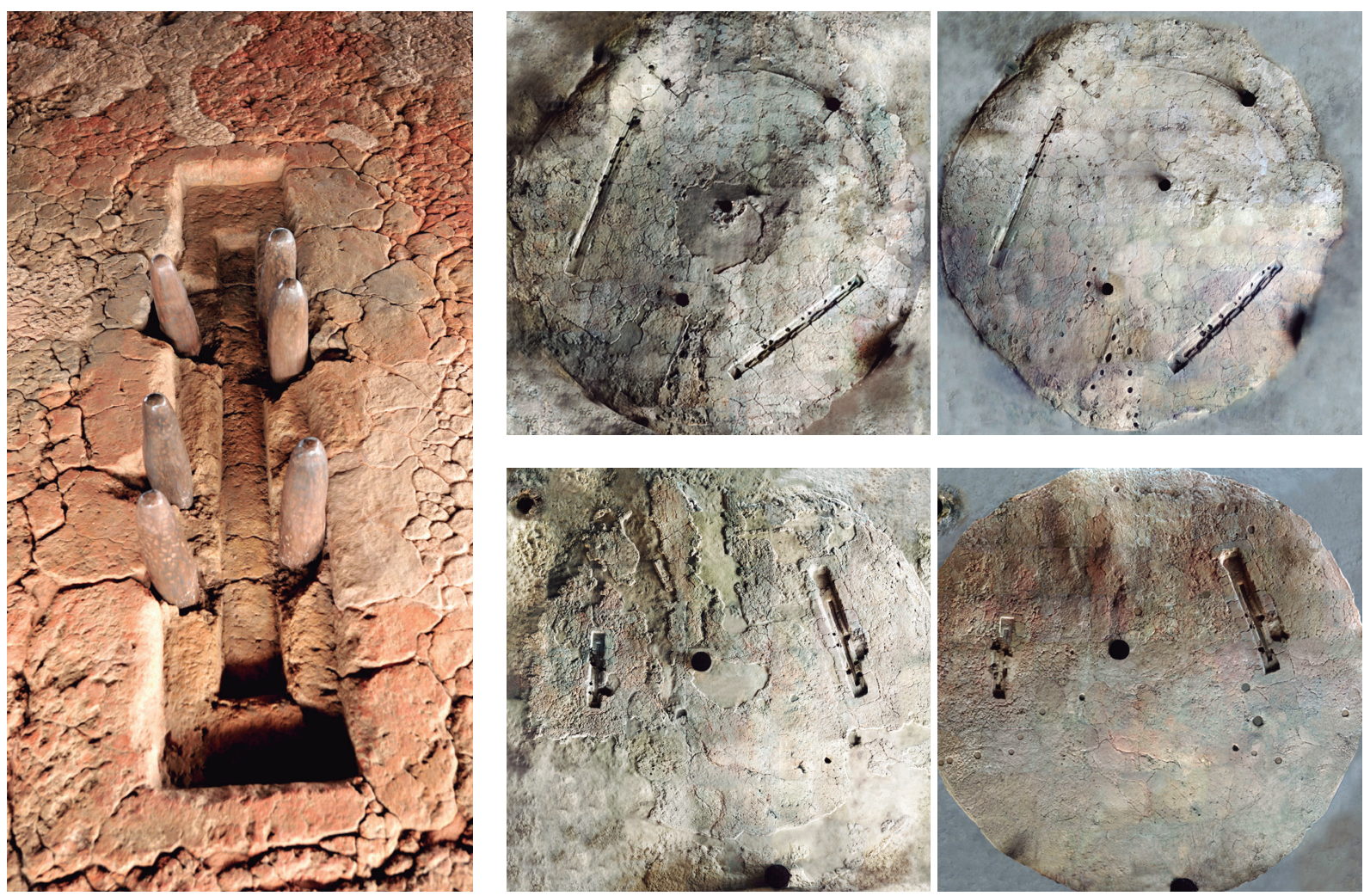

proyecto y el lugar, se decidieron desarrollar charlas $\mathrm{y}$ coloquios en las escuelas y colegios anteriormente citados, adaptando un enfoque lúdico que dinamizara la actividad, favoreciendo a su vez un contexto cálido en el que los alumnos pudieran expresarse con soltura.

Partiendo de unas nociones básicas en psicopedagogía, fueron planteados unos estudios previos, que culminaron en la elaboración de diversos instrumentos y herramientas de carácter lúdico-didácticas, de los cuales fueron seleccionados los siguientes:

Cuadernos didácticos en sensibilización patrimonial: englobados en lo que finalmente se denominó Programa "Cochasquí y yo". Cada cuaderno disponía de fichas didácticas con ejercicios a realizar durante el desarrollo de la experiencia en el aula, quedando las líneas temáticas del siguiente modo:

Bloque I: "El cuaderno del explorador" (5-8 años): propone una primera aproximación acerca de la diversidad de elementos presentes en el Parque, presentado todo ello mediante dibujos esquemáticos, laberintos, sopa de letras, textos incompletos, etc. Ejercicios que
De izquierda a derecha y de arriba a abajo:

Figura 17 (página anterior)

Detalle de uno de los canales donde se aprecian los plintos reproducidos.

Figura 18

Plataforma inferior antes y después de la reintegración volumétrica.

Figura 19

Plataforma superior, estado inicial y final tras la intervención restaurativa. 
permiten al alumno conocer las estructuras piramidales antes y después de su enterramiento, así como la fauna y la vegetación característica.

Bloque II: "El cuaderno del explorador" (9-13 años): en él se pretende dar a conocer qué elementos engloba y refiere el término patrimonio, a través de un paralelismo entre sus enseres personales y los vestigios arqueológicos del Parque.

Bloque III: "El cuaderno del conservador" (14-18 años): en cuyo contenido se pretendía presentar las diferentes profesiones encargadas de velar por la valoración, conservación y difusión del patrimonio, señalando la labor de los conservadores-restauradores, como una de las figuras que se encargan de la preservación del bien en su consistencia física. Todo esto mediante actividades sobre cómo actúan los agentes de deterioro y la simulación de una rueda de prensa al conservador-restaurador con el fin de resolver dudas o curiosidades de los alumnos, recalcándoles al mismo tiempo la acción ciudadana como garantía de salvaguardia.

Como propuestas accesorias al Programa "Cochasquí y yo", se destaca la creación de:

- Un Rompecabezas de la Pirámide no13 (5-8 años): se trata de una estructura piramidal que representa la Pirámide ${ }^{\circ} 13$, donde tienen lugar las acciones de conservación y restauración de las plataformas cerámicas durante la primera y segunda fase del proyecto. En él se representan elementos propios de la cultura Quitu-Cara, la fauna y flora de la zona, los deterioros presentes en las construcciones y la situación actual de medidas de conservación de las plataformas cerámicas. Este rompecabezas resultó ser un instrumento idóneo para los alumnos más jóvenes, porque permite testar los conocimientos previos acerca del Parque, facilitándole al técnico una base sobre la que debe iniciar el discurso teórico.

- El Puzzle de la restauración (5-13 años): es la construcción en forma ordenada de la metodología seguida en las actuaciones de conservación y restauración de las plataformas cerámicas.

\section{Observaciones previas a la práctica}

El entusiasmo suscitado, el interés mostrado por las herramientas didácticas y el amable contexto en el que se desarrollaron las actividades fueron los detonantes de esta exitosa experiencia.

Como resultado de la práctica en el primer bloque, los niños mostraron un alto interés por estas manifestaciones, sin embargo, a medida que avanzan los estudios en cursos superiores, esta predisposición disminuye. Lo mismo ocurre en el interés por el conocimiento de sus raíces culturales y el entorno natural en que se ubica el Parque. En los resultados del alumnado del segundo bloque, el número de visitas al Parque decrece y, a su vez, el interés por este tipo de manifestaciones arqueológicas. Son conocedores de que estos objetos tienen un valor inherente, pero desconocen en qué medida pueden estar vinculados con su realidad personal y comunitaria. Los alumnos muestran un comportamiento adecuado y cívico, en lo que respecta a la normativa vigente del Parque; sin embargo, muchos confiesan no comprender el por qué de estas prohibiciones. Tampoco distinguen las zonas en las que por seguridad y motivos de conservación, es preferible limitar el paso, ni entienden en qué medida su actitud y comportamiento frente al objeto cultural, puede afectar a su correcta preservación.
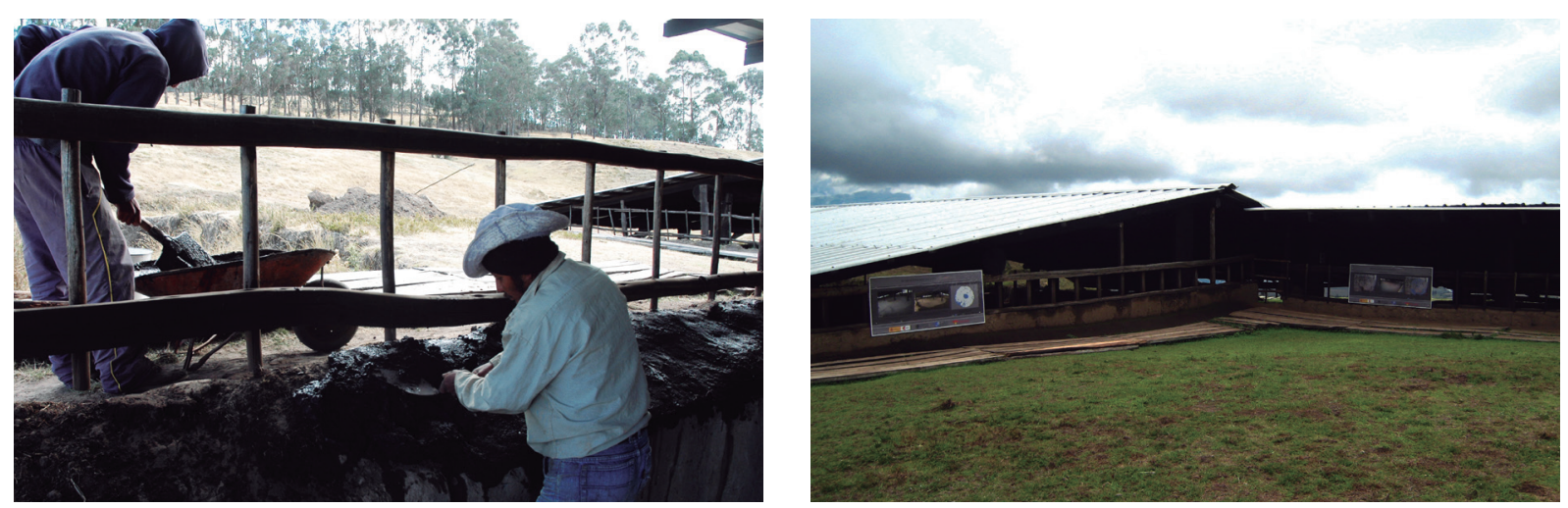
Por otra parte, aproximadamente el 70\% de los alumnos del segundo bloque manifiesta un elevado interés en la salvaguardia de los testigos culturales, debido en su mayoría al valor económico que le atribuyen, y a que se trata de manifestaciones muy antiguas. Esta opinión es compartida también por el alumnado del tercer bloque, según muestran las estadísticas en un $84 \%$. En cuanto a sus conocimientos acerca de las diferentes profesiones involucradas en el ámbito patrimonial, los alumnos destacan la figuran del arqueólogo y la del historiador, olvidando al arquitecto, los conservadores-restauradores, el personal de mantenimiento, los guías del Parque, los profesores de Ciencias Sociales, e incluso la necesaria participación ciudadana, entre otros. En este caso, los porcentajes de los resultados, tanto en el segundo y el tercer bloque, son semejantes.

\section{Observaciones tras la práctica}

Los alumnos del Bloque I manifestaron mucho entusiasmo e interés por las actividades. Debido a su corta edad, la valoración del alumnado estuvo determinada a partir de los dibujos realizados tras la práctica, siendo los elementos naturales los más representados (17\%), junto con los Bohíos (viviendas indígenas), alcanzando el mismo porcentaje, seguido de sus propias representaciones con un $16 \%$, incluyéndose dentro del Parque Arqueológico.

Los alumnos del Bloque II también realizaron dibujos, en los cuales los Bohíos se convertían en uno de los elementos más representados junto con los elementos naturales (19\%) y seguido de las pirámides con un 14\%. Los alumnos participantes manifestaron que a través de dicha actividad, comprendieron de qué manera están vinculados a este legado histórico.

De izquierda a derecha:

Figura 20 (página anterior)

Aplicación de medidas preventivas en torno a las plataformas.

Figura 21

Afiches ubicados en la pirámide 13.

Figura 22

Alumnos UTE recibiendo las explicaciones previas a la realización de la práctica.
Todo ello queda reflejado tras las encuestas finales, obteniendo unos promedios elevados en su valoración de las actividades realizadas y mostrándose interesados en continuar con este tipo de actividades.

Los alumnos que participaron en el Bloque III mostraron interés durante el transcurso de la actividad, participando en grupo y lanzando cuestiones, mostrando especial sorpresa en la variedad de disciplinas que participan en la protección y salvaguardia del patrimonio. También les sorprendió la cantidad de signos patrimoniales que definen una cultura, $y$ la importancia que tienen para la identidad de una comunidad.

\section{Conclusiones}

Como conclusión de la acciones desempeñadas durante las dos fases, cabe mencionar que este tipo de trabajos favorecen a aumentar la valoración que la población de la zona tiene por su patrimonio y, en concreto, sus bienes culturales nativos, especialmente al hacerla partícipe en este tipo de intervenciones desde los inicios del Proyecto en el año 2008 con las acciones de conservación. Transmitiéndoles desde entonces y tras la segunda fase, una mayor responsabilidad respecto a la conservación de los restos a través del trabajo diario y el conocimiento de la complejidad y esfuerzo que conlleva el desarrollo de este tipo de intervenciones. Durante ambas intervenciones, el personal de mantenimiento ha sido iniciado en los conocimientos y modo de actuación necesarios para mantener la acción de conservación, restauración y salvaguarda de los restos intervenidos, haciéndoles de este modo cómplices de este tipo de acciones.

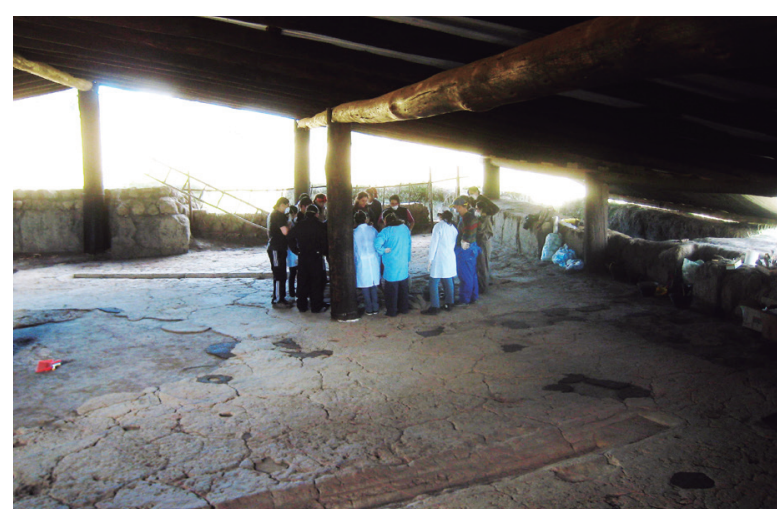


Cabe añadir que con la finalidad de contribuir a las mejoras explicativas que se desarrollan por los guías del Parque, fueron reproducidos en arcilla los conos denominados plintos (los originales, que se encuentran en el museo del Parque, están elaborados en piedra andesita), estas imitaciones fueron ubicadas en varios de los orificios de uno de los canales de la plataforma superior, produciéndose así un ligero aumento en el atractivo que tienen estos importantes vestigios, y contribuyendo con ello a facilitar la comprensión sobre la hipótesis sostenida por Valentin Yurevich, acerca de que estas plataformas pudieron ser empleadas por los antiguos Quitu-Cara como calendarios solar y lunar.

Teniendo en consideración los resultados obtenidos en los bloques didácticos realizados gracias a la colaboración de los colegios y escuelas de las comunidades de Cochasquí y Malchinguí, cabe indicar que es importante iniciar estas tareas de sensibilización desde los primeros años, sin olvidar, especialmente, el patrimonio autóctono. Creándose unos lazos entre el pasado y presente que refuerzan la identidad cultural desde la más tierna infancia y favoreciendo de este modo la multiculturalidad.

A partir de estos estudios previos, hemos podido observar cómo en alumnos de mayor edad, la atención y el interés hacia su propio patrimonio decrece, posiblemente por no ser un tema tratado de forma continua $y$, por tanto, puede no generar suficiente motivación en los más jóvenes. Desconociendo en qué grado el patrimonio arqueológico puede estar vinculado con su entorno particular.

El profesorado presente en la realización de las actividades valora al $100 \%$ la continuación y sostenibilidad de este tipo de actividades. Afirman que la identificación cultural del joven con su patrimonio es positiva y complementaria para su enriquecimiento educativo, coincidiendo con el proyecto en la necesidad de fomentar este tipo de iniciativas de forma constante, mostrándose participativos en las futuras intervenciones, complementando la formación académica con el crecimiento intelectual en todas sus facetas, como por ejemplo, a través de unidades o maletas didácticas que dibujen una línea transversal a las asignaturas comunes, siempre desde una mirada lúdica y atractiva, que permita una mayor atención y asimilación de conceptos, mostrando el patrimonio cultural como algo formativo a la vez que curioso, cercano y divertido. Para ello sería conveniente ini- ciar acciones que pretendan, desde el conocimiento y reconocimiento del objeto, establecer un vínculo tanto personal como colectivo. De tal modo que el alumno se sienta involucrado en la conservación, tanto de su patrimonio tangible como intangible, gracias a esta formación transversal propuesta.

Estas pretensiones abarcan la creación de maletas didácticas más desarrolladas que tendrán en consideración los resultados obtenidos en estos estudios previos, y en los cuales se mostrará colaboración con la Universidad Tecnológica Equinoccial de Quito, Ecuador.

En resumen, la salvaguarda debe ser un elemento clave para la sociedad, en especial en los más jóvenes, los cuales deben implicarse de forma más activa en su patrimonio cultural, ya que además de propiciar la cohesión social, son elementos generadores de desarrollo emocional y la activación económica de la zona. El primer paso hacia la verdadera apropiación social de este patrimonio arranca desde un conocimiento y estima del objeto, estableciendo un vínculo personal entre los distintos miembros de una comunidad, desarrollando el crecimiento progresivo e incluyéndolo en su entorno social y cotidiano, haciéndolo partícipe en crecimiento formativo y educativo. De tal manera que el usuario de este patrimonio se sienta responsable en la conservación del objeto, tanto en su instancia física como en su valor cultural, como elemento de identidad personal y colectiva.

Estas estructuras arquitectónicas deben estar protegidas de acuerdo con los criterios relativos a la conservación y restauración de monumentos arqueológicos y lugares de interés cultural. Teniendo en cuenta que a su vez, este continúa formando parte de tradiciones vivas de las poblaciones autóctonas, ya que Cochasquí sigue siendo un lugar ceremonial y ritual para indígenas, atribuyéndole cualidades como foco energético y curativo, además de ser considerado como lugar de interés para la realización de eventos. La concienciación cada vez mayor del público en lo que respecta a esta dimensión fundamental del patrimonio es una necesidad absoluta si se pretenden lograr medidas concretas para la salvaguardia de los vestigios del pasado. Esto significa desarrollar una comprensión mayor de los valores representados por los propios bienes culturales, así como respetar el papel que desempeñan tales monumentos y emplazamientos en la sociedad contemporánea. 

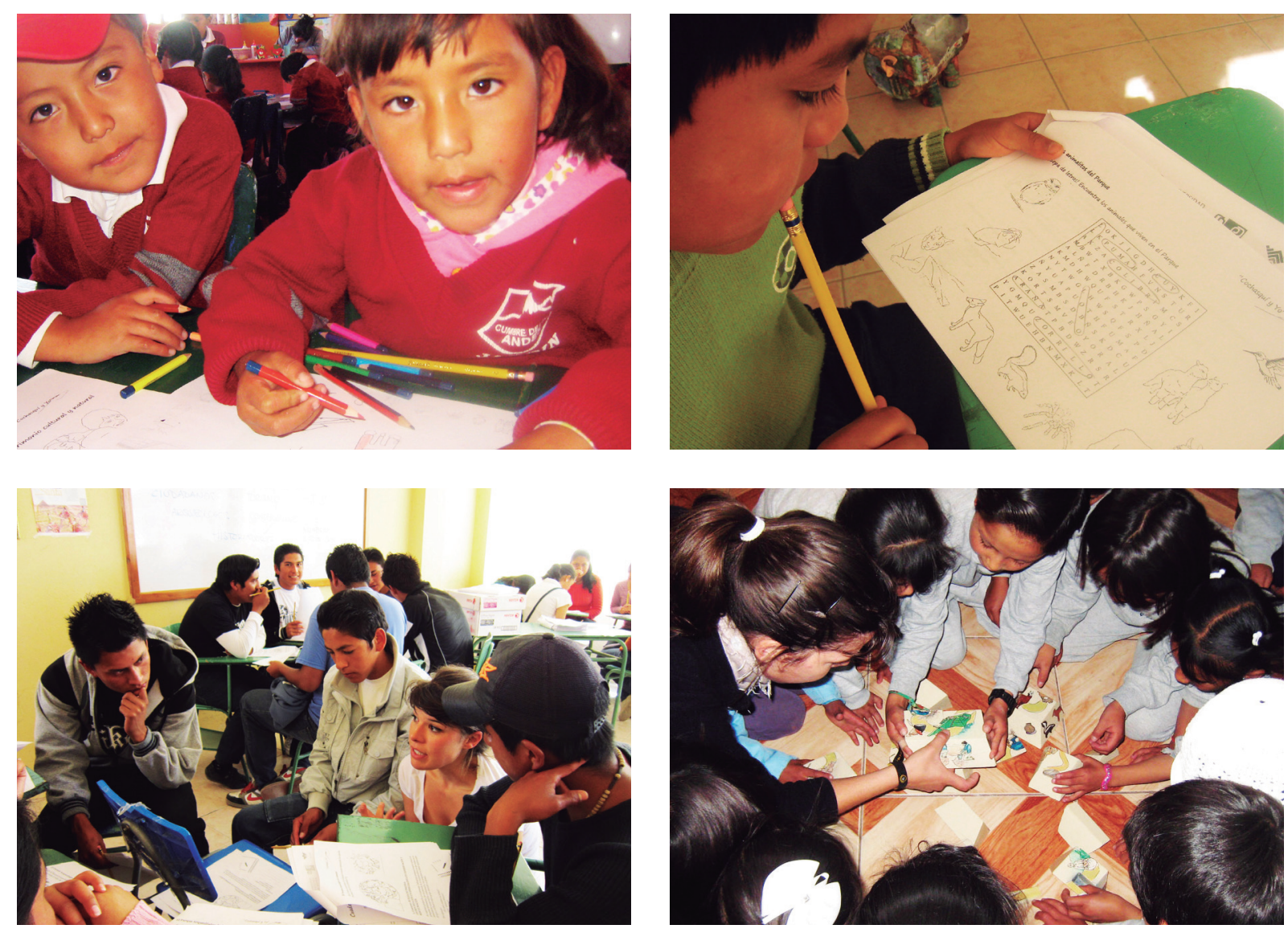

En este sentido es importante facilitar la cooperación internacional entre todos aquellos que tengan un interés en la preservación del patrimonio cultural, con el objeto de mejorar el respeto y la comprensión a escala mundial de las diversas expresiones y valores de cada cultura.

\section{Agradecimientos}

Las autoras de esta comunicación agradecen expresamente el apoyo recibido de la Agencia Española de Cooperación Internacional para el Desarrollo (AECID) del Ministerio de Asuntos Exteriores de España, a través de la subvención concedida al Proyecto 08-CAP2-0906, y a la cofinanciación de este por parte de La Universidad Politécnica de Valencia, España y del Gobierno Autónomo Descentralizado de la Provincia de Pichincha, Ecuador. Y que han contribuido de forma determinante a hacer posible las investigaciones y la obtención de los resultados que se exponen en este artículo.

De izquierda a derecha y de arriba a abajo:

Figura 23

Alumnos de la escuela Pedro Moncayo durante la realización de las actividades.

Figura 24

Alumno resolviendo una de las actividades del Bloque II.

Figura 25

Instantánea durante la realización de la experiencia con alumnos del Bloque III.

Figura 26

Alumnos de la escuela 13 de Abril de Cochasquí completando el rompecabezas. 


\section{Bibliografía}

AAVV. (2008). Guías de Actividades Patrimoniales. Proyecto conjunto MINEDUC / UNESCO. Programa Patrimonio Educacional. Identidad y futuro. UNESCO, Santiago.

Ballart, J. (1997). El Patrimonio histórico y arqueológico: valor y uso. Ariel Patrimonio, Barcelona.

Brandi, C. (2002). Teoría de la restauración. Alianza Editorial.

Carrascosa, B. y Medina, O. Mª (2010). Cooperación al Desarrollo Cultural y Formativo para la Puesta en Valor de las Pirámides Preincaicas de Cochasquí, Ecuador. Universidad Politécnica de Valencia.

Carrascosa, B., Medina, O. Ma. (2012). La Conservación y Restauración de las plataformas cerámicas preincaicas de Cochasquí. II Fase: Cooperación al Desarrollo Cultural y Formativo para la puesta en valor de las
Pirámides preincaicas de Cochasquí, Ecuador. Universidad Politécnica de Valencia.

Doménech, T., Valentín, N., Vaillant, M. (2003). Una mirada hacia la conservación preventiva del Patrimonio Cultural. Universidad Politécnica de Valencia.

Ferrero y de Loma-Osorio, G. (2011). Identificación y Formulación de proyectos de cooperación al desarrollo. Gestión de ciclo del proyecto y enfoque del marco lógico. Cuadernos de cooperación. Universidad Politécnica de Valencia.

Gómez, M. L. (1998). La Restauración. Examen científico aplicado a la conservación de obras de arte. Madrid, Ed. Cátedra.

Llonch, N., Santacana, J. (2011). Claves de la museografía didáctica. Lleida, Ed. Milenio.

Matteini, M., Moles, A. (2001). La Química en la Restauración. Ed. Nerea.

Figura 27

Dibujo libre de un alumno del Bloque I.

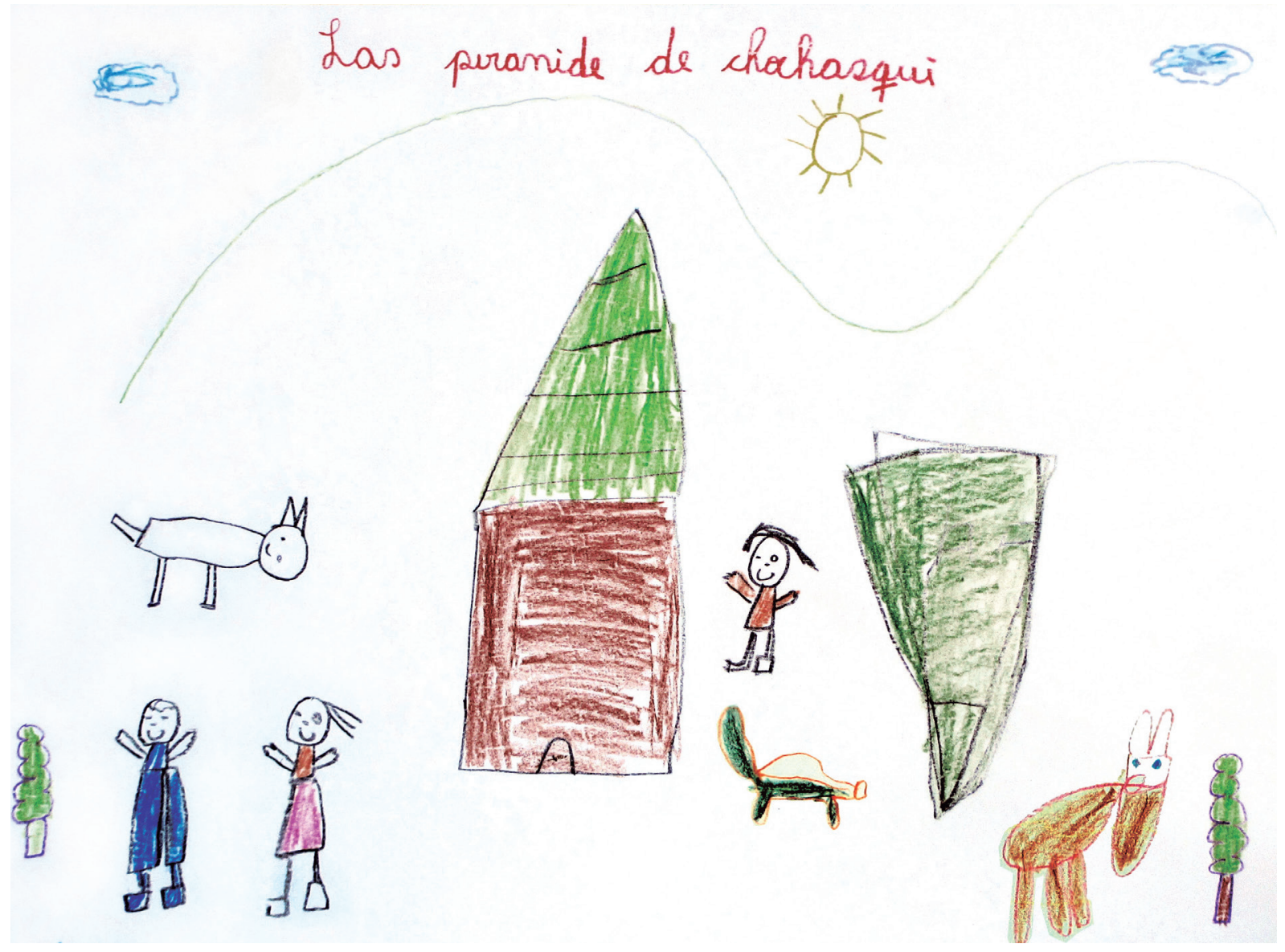

